\title{
A Qualitative Examination of Emotional Experiences During Physical Activity Post-metabolic/Bariatric Surgery
}

\author{
Emily H. Feig ${ }^{1,2} \cdot$ Lauren E. Harnedy $^{1}$ · Julia Golden ${ }^{1} \cdot$ Anne N. Thorndike ${ }^{3,4} \cdot$ Jeff C. Huffman ${ }^{1,2}$ - Christina Psaros ${ }^{1,2}$
}

Received: 2 June 2021 / Revised: 11 November 2021 / Accepted: 14 November 2021 / Published online: 20 November 2021

(c) The Author(s), under exclusive licence to Springer Science+Business Media, LLC, part of Springer Nature 2021

\begin{abstract}
Purpose Physical activity is critical for weight loss maintenance and cardiometabolic disease prevention after metabolic/ bariatric surgery (MBS), but few patients meet recommended levels. While difficulties meeting physical activity recommendations are common in the general population, those who have undergone MBS may have unique psychological barriers to activity that impede success, including negative associations with physical activity that are related to a long history with obesity, weight stigma, and physical limitations. This qualitative study aimed to better understand the positive and negative emotional experiences of post-MBS patients with regard to physical activity to inform the development of an emotion-focused intervention to increase physical activity after MBS.

Methods Adults who had MBS in the past 2 years completed semi-structured interviews and psychological/behavioral questionnaires. After transcription, a codebook was developed using inductive and deductive methods. Coded data were analyzed using content analysis.

Results Participants were 23 adults (78\% female). Contexts that contributed to positive emotions during physical activity included an enjoyable type of exercise, social interaction, mindfulness during exercise, and mastery. Contexts that contributed to negative affect were more unique to the MBS population, including all-or-nothing thinking about exercise, using distraction, depression, negative body image, exercising only for weight loss, and the COVID-19 pandemic.

Conclusion For most participants, emotional factors were relevant in the decision to be physically active and in their ability to maintain their habits. An intervention that encourages factors that lead to positive affect and addresses factors that lead to negative affect could be effective in increasing physical activity following MBS.
\end{abstract}

Keywords Physical activity $\cdot$ Bariatric surgery $\cdot$ Psychology $\cdot$ Positive emotions $\cdot$ Health behavior change

\section{Key Points}

- Emotional barriers may explain why post-MBS patients do not meet exercise guidelines.

- Contexts leading to positive emotions during exercise are similar to other groups.

- Contexts leading to negative emotions are more specific to this population.

- Exercise interventions should target emotional barriers and build positive affect.

\section{Emily H. Feig}

efeig@mgh.harvard.edu

1 Department of Psychiatry, Massachusetts General Hospital, 55 Fruit St, Boston, MA 02114, USA

2 Department of Psychiatry, Harvard Medical School, 25 Shattuck St, Boston, MA 02115, USA

3 Department of Internal Medicine, Massachusetts General Hospital, 55 Fruit St, Boston, MA 02114, USA

4 Department of Internal Medicine, Harvard Medical School, 25 Shattuck St, Boston, MA 02115, USA

\section{Introduction}

Obesity is a major public health concern, and metabolic and bariatric surgery (MBS) is the most effective treatment available for severe obesity [1]. Adherence to health behaviors like a healthy diet and physical activity is critical for long-term weight loss maintenance and reducing the incidence of cardiovascular disease after MBS [2], as they are for individuals with obesity broadly. However, physical activity levels are low in the post-MBS population, with minimal changes in moderate-to-vigorous physical activity (MVPA) from pre- to post-surgery, and less than $10 \%$ meeting the population-level guideline of 150 min of MVPA per week [3, 4]. This pattern is distinct from individuals maintaining non-surgical weight loss, who have been shown to engage in high levels of MVPA [5]. 
While difficulties meeting physical activity recommendations are common across the general population, those who have undergone MBS may have unique psychological barriers to activity that impede success related to their obesity history. People with obesity report higher rates of exercise avoidance due to body image concerns [6], and those who have MBS have typically lived with obesity for many years prior to surgery [7] and therefore are likely to have experienced exercise avoidance. Prior negative experiences with physical activity due to physical limitations may also lead to low self-efficacy in MBS patients before surgery. Although these physical barriers may be reduced after drastic weight loss, individuals may not have an associated increase in confidence and knowledge about safe and effective activities [8]. Furthermore, new physical limitations related to excess skin can present after surgery. Based on these and other factors, MBS patients are likely to have negative associations with physical activity and to remember prior experiences of negative emotions during exercise. These negative associations can be highly detrimental in making and sustaining a behavior change, despite the fact that they are making a significant commitment to a lifestyle change by having surgery.

Conversely, the importance of positive associations with physical activity is detailed by the Upward Spiral Theory of lifestyle change, which describes how positive affect during a health behavior is critical for reinforcement of that activity [9]. The more one engages in the given behavior, the more endogenous resources they build and incorporate, which further heightens the positive affect experienced. MBS patients may be missing out on this "upward spiral" due to a lack of positive physical activity experiences and ongoing psychological barriers [10].

Several qualitative studies have examined barriers to activity in the MBS population [8, 11]. However, none has focused specifically on the role of emotional factors, which may be uniquely relevant in this cohort. With the Upward Spiral Theory as a framework, better understanding the positive and negative emotions that MBS patients experience during a bout of physical activity and how they impact adherence to this health behavior could help elucidate the reasons behind the lack of success that a majority of patients have in this area. Furthermore, examining the contexts that contribute to positive and negative affect during physical activity in a sample of participants with a range of physical activity levels could allow for more effective intervention on physical activity for those who are not successful. Therefore, the present qualitative study aimed to understand the emotions experienced during physical activity, as well as the contexts that led to positive and negative emotions, in a sample of post-MBS adults, to inform tailoring of behavioral interventions for this population.

\section{Methods}

\section{Participants and Setting}

This study was the first phase of a physical activity intervention development trial using the ORBIT model for behavioral treatment development [12]. Participants were adults who had undergone MBS at a large northeastern academic medical center within two years prior to study enrollment. Exclusion criteria included inability to speak and read English, cognitive deficits limiting the ability to participate (measured with a 6-item screen [13]), illness likely to lead to death in the next 6 months, current severe mental illness assessed via the Mini International Neuropsychiatric Interview [14], current substance use disorder (defined as a score $\geq 8$ on the Alcohol Use Disorders Identification Test [15], and/or $\geq 3$ on the Drug Abuse Screening Test [16]), and lack of telephone access. Recruitment was conducted with the goal of eliciting a variety of perspectives on emotional challenges to being physically active among individuals with a history of bariatric surgery, rather than a goal of generalizability of the sample, per established qualitative methods [17]. Specifically, this included a preference for racial/ethnic minorities to increase the diversity of the sample, as existing literature is comprised of predominantly white participants, and the recruitment hospital site's population is also predominantly white. This was achieved by searching the hospital's electronic medical record database specifically for patients who identified as a racial or ethnic minority and preferentially contacting those patients. Participants with low physical activity [18] ( $<150 \mathrm{~min} /$ week of MVPA), assessed via the International Physical Activity Questionnaire - Short Form [19], were also preferentially selected in order to have a balanced sample of participants engaging in higher and lower amounts of physical activity [17].

Participants were recruited between September 2019 and October 2020. Lists of patients with surgery in the appropriate time frame were pulled from the hospital system's electronic medical record and opt-out letters were mailed to eligible patients with permission from their MBS surgeon, followed by a recruitment call. All participants provided verbal consent to participate in the study. The study's procedures were approved by the institution's Institutional Review Board.

\section{Quantitative Data Collection}

Demographic, weight history, and psychological data were obtained via participant self-report through an online survey on REDCap. Participants retrospectively self-reported 
their height and weight at the start of the surgery process, at the time of surgery, and at the time of survey completion. For two participants who did not complete the online survey, demographic and weight history data were collected from the electronic medical record. Psychological questionnaires in this online survey included validated measures of optimism (Life Orientation Test-Revised [LOT-R] [20]), affective state (Positive and Negative Affect Schedule [PANAS] [21]), depression and anxiety (Hospital Anxiety and Depression Scale [HADS] [22]), barriers to being active (Barriers to Being Active Quiz [BBAQ] [23]), self-efficacy for exercise (Self-Efficacy For Exercise Scale [SEES] [24]), and internalized weight bias (Modified Weight Bias Internalization Scale [WBIS-M] [25]). These measures were chosen to capture psychological constructs that were asked about in the interviews in a quantitative and directly comparable way, to characterize the sample.

\section{Qualitative Interviews}

The function of the qualitative interviews was to better understand how and why emotions affect physical activity behavior and in what contexts. A female clinical psychologist trained in qualitative methods and with clinical and research experience with MBS patients (EHF) completed all interviews by phone. Telephone interviews are considered to be a valuable, viable method for conducting qualitative research [26]. Participants were informed that the reason for the study was to influence the development of a physical activity intervention. Prior to conducting the interviews, we developed a semi-structured interview guide based on the study aims (e.g., identifying emotions experienced during physical activity, assessing contexts that contribute to negative and positive emotions), prior qualitative research exploring positive psychological constructs in medical patients [27], and feedback from local qualitative research experts. The interview was piloted with 3 participants, after which authors reviewed transcripts and adjusted the interview based on gaps that emerged. Pilot interviews were pooled as part of the final data sample. See Supplementary Table 1 for sample questions from the interview. Interviews lasted 45 minutes and were audio-recorded with participant consent, then professionally transcribed and reviewed by the principal investigator for completeness. Interviews were conducted until we reached thematic saturation, which determined the sample size [28]. All participants who completed the interview and online survey were paid $\$ 35$.

\section{Data Analysis}

Quantitative measures were summarized with means and standard deviations. A content analysis approach was applied to data analysis. The principal investigator (EHF) read all transcripts and drafted an initial codebook with guidance from qualitative and content experts $(\mathrm{CP}, \mathrm{JCH})$, using inductive and deductive methods. Three coders (EHF, JG, LH) coded the data (at least two coders per interview). The principal investigator reviewed each interview for coding discrepancies and to ensure reliability. The coding team met regularly to establish operational definitions of codes and to resolve discrepancies, and an audit trail of discussions was maintained. Themes were then derived from the data. All qualitative coding was completed with Dedoose Software.

\section{Results}

\section{Participant Characteristics}

Opt-out letters were mailed to 245 patients. We then followed up the letters with phone calls for 176 patients of whom we spoke with 49 (the rest never answered the phone or responded to voicemails). Ten of these patients were ineligible and 9 were not interested in participating, leaving 30 who were interested and eligible at screening. Of these, $7 \mathrm{did}$ not follow through with study participation, resulting in a final sample of 23 participants. Descriptive information and scores on psychological measures are reported in Table 1 . Six participants scored above the clinical cutoff $(\geq 8)$ for anxiety, one scored above the clinical cutoff for depression, and six scored above the cutoff $(\geq 4)$ for a high internalized weight bias score [29].

\section{Qualitative Result Overview}

Qualitative results are organized according to Fig. 1. Positive and negative emotional experiences with physical activity are described, followed by the contexts that contributed to those emotional experiences. Additional supporting quotations can be found in Table 2 .

\section{Experiences of Positive Affect Associated with Physical Activity}

Descriptions of positive affect associated with physical activity were common. Frequently noted specific positive emotions included excitement, determination, pride, accomplishment, and joy. Many reported an improvement in mood during or after physical activity, although for some, this was a complex trajectory:

So as I started, I was like, 'I don't really want to do this.' And when I started doing the squats, I'm like, 'See? Because you haven't done these squats in a 
Table 1 Sample characteristics and scores on psychological measures at the time of study participation

\begin{tabular}{|c|c|}
\hline Sample demographics & $\mathrm{M}(\mathrm{SD})$ or $N(\%)$ \\
\hline Female & $18(78 \%)$ \\
\hline Age & $47.35(15.04)$ \\
\hline \multicolumn{2}{|l|}{ Race/ethnicity } \\
\hline Non-Hispanic White & $12(52 \%)$ \\
\hline Non-Hispanic Black & $5(22 \%)$ \\
\hline Hispanic/Latinx & $6(26 \%)$ \\
\hline$\%$ total weight loss & $30.31(11.66)$ \\
\hline \multicolumn{2}{|l|}{ BMI category } \\
\hline Normal & $2(9 \%)$ \\
\hline Overweight & $11(48 \%)$ \\
\hline Obese & $10(43 \%)$ \\
\hline MVPA $^{\mathrm{a}}$ (minutes/week) & $199.10(203.95)$ \\
\hline$<150 \mathrm{~min} /$ week $\mathrm{MVPA}^{\text {a }}$ & $12(52 \%)$ \\
\hline$\geq 150 \mathrm{~min} /$ week $\mathrm{MVPA}^{\mathrm{a}}$ & $11(48 \%)$ \\
\hline Psychological measure & $\mathrm{M}(\mathrm{SD})$ \\
\hline Optimism (LOT-R ${ }^{\mathrm{b}}$, range $\left.0-24\right)$ & $8.71(5.65)$ \\
\hline Positive affect $\left(\right.$ PANAS $^{\mathrm{c}}$, range $\left.10-50\right)$ & $34.95(8.03)$ \\
\hline Negative affect $\left(\right.$ PANAS $^{\mathrm{c}}$, range $\left.10-50\right)$ & $18.19(5.75)$ \\
\hline Weight bias internalization (WBIS-M ${ }^{\mathrm{d}}$, range $1-7$; cutoff $\geq 4$ ) & $2.89(1.54)$ \\
\hline Depression $\left(\mathrm{HADS}^{\mathrm{e}}\right.$, range $0-21$; clinical cutoff $\geq 8$ ) & $2.90(3.09)$ \\
\hline Anxiety $\left(\mathrm{HADS}^{\mathrm{e}}\right.$, range $0-21$; clinical cutoff $\geq 8$ ) & $6.68(4.26)$ \\
\hline Barriers to being active $\left(\mathrm{BBAQ}^{\mathrm{f}}\right.$, range $\left.0-63\right)$ & $18.57(11.83)$ \\
\hline Time (range 0-9) & $3.33(2.46)$ \\
\hline Social influence (range 0-9) & $2.71(2.12)$ \\
\hline Lack of energy (range 0-9) & $3.86(2.95)$ \\
\hline Lack of willpower (range 0-9) & $4.48(3.46)$ \\
\hline Fear of injury (range 0-9) & $0.57(0.81)$ \\
\hline Lack of skill (range 0-9) & $1.24(1.81)$ \\
\hline Lack of resources (range 0-9) & $2.38(2.25)$ \\
\hline Self-efficacy for exercise $\left(\mathrm{SEES}^{\mathrm{g}}\right.$, range $\left.0-90\right)$ & $43.10(22.49)$ \\
\hline
\end{tabular}

${ }^{a} M V P A$ moderate-to-vigorous physical activity measured with the International Physical Activity Questionnaire Short Form [19], ${ }^{\mathrm{b}}$ LOT-R Life Orientation Test - Revised [20], ${ }^{\mathrm{c}}$ PANAS Positive and Negative Affect Scale [21], ${ }^{\mathrm{d}} W B I S-M$ Weight Bias Internalization Scale - Modified, Cutoff to denote high weight bias internalization has been proposed as above the midpoint of the scale [29], ${ }^{\mathrm{e}} H A D S$ Hospital Anxiety and Depression Scale [22], ${ }^{\mathrm{f}} B B A Q$ Barriers to Being Active Quiz [23], ${ }^{\mathrm{g}}$ SEES Self-Efficacy for Exercise Scale[24] while, your body's feeling this way. And last week you were killing it with the squats.' So [...] I have this big inner critic that, I think, really hurts my efforts. But the more I did the squats, and then I was doing the core work, the more that I saw my energy getting better. And I felt positive and I extended the workout. [F, age 31, $250 \mathrm{~min} /$ week MVPA, 23\% TWL].

This participant's experience demonstrated factors that led to her negative emotions as she started the exercise (low self-efficacy, negative self-evaluation). This was followed by a shift wherein her energy started to improve from doing the physical movement, which led to feeling more positive and ultimately deciding to extend the workout.

\section{Contexts that Contributed to Positive Affect}

Context 1: Enjoyment of the activity. Some participants noted enjoyment of particular types of activity as a factor that led to positive affect. For example,

For me, everything is about the emotions I connect with it. So if I have an experience that makes me have some sort of negative emotion, I connect that thing to something negative, and I'm afraid it's going to be negative the rest of the time. But if I'm able to connect that with a positive feeling, like I did with the gym, like I was able to do with rock climbing, or like I do with my walks, then yeah, I'm more likely 


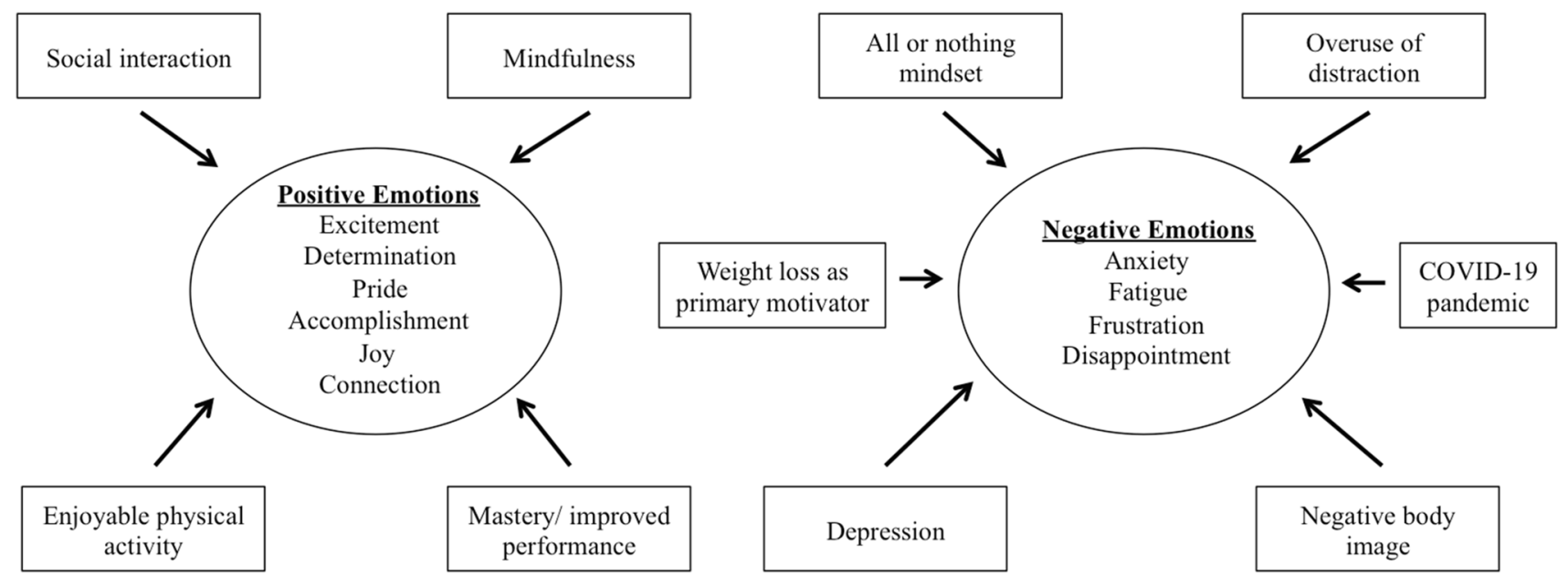

Fig. 1 The most commonly noted positive and negative emotions experienced during a bout of physical activity, and the contexts that contributed to these emotions

to do it rather than avoid it. [F, age 35, $150 \mathrm{~min} /$ week MVPA, 38\% TWL].

Context 2: Social connection. Others noted social connection as a factor that increased positive feelings. For example, one participant felt a strong sense of belonging as part of her workplace walking group:

There's a group of us that are walkers and then [...] a group of some of them that are more-- we call them the sitters. [F, age 67, $90 \mathrm{~min} /$ week MVPA, 24\% TWL].

Context 3: Mindfulness. A third factor that led to positive affect related to physical activity was taking a mindful approach. For example,

After surgery, walking has been a really good way for me to connect to my body because previously walking was so painful. My knees hurt, my back hurt, I was out of breath. And I do this thing when I walk now where I just put all of my thoughts into my knees and I can't feel a thing. Nothing hurts. And I sometimes will think, $[\ldots]$ isn't that so awesome that [...] I can place one foot in front of the other and not be in pain and feel really like all of my body is kind of firing on all cylinders. [F, age 31, $130 \mathrm{~min} /$ week MVPA, 33\% TWL].

Context 4: Mastery. Finally, demonstrating mastery or improved performance led to positive emotions such as excitement and interest for some participants:

Almost excited in a way because you always want to be - you want to see if you can lift a little bit more, an extra five pounds or an extra rep or whatever. $[\mathrm{F}$, age 25, $425 \mathrm{~min} /$ week MVPA, 41\% TWL].

\section{Experiences of Negative Affect Associated with Physical Activity}

The most commonly noted negative emotions were anxiety, fatigue, and frustration. The majority of data mentioning anxiety attributed the emotion to external factors. However, several participants described anxiety about the physical activity itself. These participants were meeting physical activity guidelines, so perhaps the anxiety helps to motivate them:

...almost feeling a fear. Like, if you get off the wagon, there will be a catastrophe. [F, age 42, $250 \mathrm{~min} /$ week MVPA, 23\% TWL].

There were three participants who described an overall negative perception of physical activity, for example,

Well, I've never been great at it. Okay? There were periods of time where I would do it, but I just don't like it. Okay? I just don't like exercising. [F, age 63, 0 min/week MVPA, 34\% TWL].

These participants all reported less than the recommended 150 minutes/week MVPA, and two of them had not been successful in weight loss, losing less than $20 \%$ of their starting body weight. All three participants also had trouble identifying any strong emotions during physical activity.

\section{Contexts that Contribute to Negative Affect}

Context 1: Use of Distraction. Using distraction to get through a bout of exercise was associated with a more negative overall experience of physical activity. Several participants relied on distraction to get through their workouts 
Table 2 Additional quotations to support themes

Theme Quotation

Positive affect associated with physical activity

Physical activity improves mood

Pride

"Yep. Walk in feeling like crap and walk out feeling so much better." [M, age 50, $120 \mathrm{~min} /$ week MVPA $\left.{ }^{\mathrm{a}}, 8 \% \mathrm{TWL}^{\mathrm{b}}\right]$.

"I was proud of myself that I still had enough inner energy to do all the things that I wanted to do. Even though sometimes I kind of was like, do I really want to do more abs? I just pushed through because I'm like, yes, I'm going to do it, it's great, it's fun, it's nice." [F, age 21, 420 $\mathrm{min} /$ week MVPA ${ }^{\mathrm{a}}, 38 \% \mathrm{TWL}^{\mathrm{b}}$ ].

Accomplishment

"And then once I was working out [...] I just felt like I was getting stronger. That was just like, 'All right. This was a good decision.' I just felt better about myself [...] once I was like midexercise." [F, age 25, $475 \mathrm{~min} /$ week $\mathrm{MVPA}^{\mathrm{a}}$, $\left.41 \% \mathrm{TWL}^{\mathrm{b}}\right]$.

Contexts contributing to positive affect

Enjoyment of the activity

"I really enjoy Zumba, and I think that's one of the reasons I've been able to incorporate that more easily is because I really find it fun [...] It's not a physical high. It feels like an emotional high.” [F, age 61, $150 \mathrm{~min} /$ week $\mathrm{MVPA}^{\mathrm{a}}, 22 \% \mathrm{TWL}^{\mathrm{b}}$ ].

Mastery/improved performance

"Now, I pretty much put my bike in the car and bring it someplace fun to ride, and then I look forward to that, and then I do the ride. And yeah, I track my statistics, and it gives me something to measure it by and kind of achieve, like how many miles I'll do and how fast I'll do it. It keeps me more interested." [M, age 59, $135 \mathrm{~min} /$ week MVPA $^{\mathrm{a}}, 39 \% \mathrm{TWL}^{\mathrm{b}}$ ].

"I was excited. I was amped up to go because I woke up early that day and actually did kickboxing that day, too. That same morning. I went to the gym after the kickboxing." [F, age 21, $420 \mathrm{~min} /$ week MVPA ${ }^{\mathrm{a}}, 38 \% \mathrm{TWL}^{\mathrm{b}}$ ].

Negative affect associated with physical activity

Stress/anxiety

"Stress is the first emotion that comes to mind when I think of going to the gym." [M, age 50, $120 \mathrm{~min} /$ week MVPA $\left.{ }^{\mathrm{a}}, 8 \% \mathrm{TWL}^{\mathrm{b}}\right]$.

"Before I go to the gym or I'm about to work out, I do feel anxious because I feel like I might not meet the goal or I might be a little bit weaker than the last day that I worked out." [F, age 21, $420 \mathrm{~min} /$ week MVPA ${ }^{\mathrm{a}}, 38 \% \mathrm{TWL}^{\mathrm{b}}$ ].

Frustration

"Tired and worn out and I would say frustration that I'm not-- that I don't have the true guidance at the gym to do a certain regimen. I don't have a trainer. I don't have a gym buddy. That would be my only frustration, really. I've been just doing it kind of willy-nilly." [M, age 50, $120 \mathrm{~min} /$ week MVPA $\left.{ }^{\mathrm{a}}, 8 \% \mathrm{TWL}^{\mathrm{b}}\right]$.

Fatigue

"So yesterday I really did not want to work out at all. I would say I was kind of like, 'Oh my God. I'm too tired. I don't feel like doing it' type thing. But really the bike is downstairs in the basement. I went downstairs. I was like, 'Whatever. Just get on it' type thing, right?' [F, age $25,475 \mathrm{~min} /$ week $\mathrm{MVPA}^{\mathrm{a}}$, $41 \% \mathrm{TWL}^{\mathrm{b}}$ ].

General dislike

"I just have never enjoyed it. I was never one to go to the gym. I mean I get on the treadmill now and work. But it's more of a forced chore in the morning than something I would enjoy doing." [ID 10: M, age 48, $100 \mathrm{~min} /$ week MVPA ${ }^{\mathrm{a}}$, 20\% $\mathrm{TWL}^{\mathrm{b}}$ ].

Negative mood triggered by external factors

"How I'm feeling about other things affects how I'm feeling about exercise much more than how I feel about the exercise, itself, or at least equally as much.” [F, age 63, $0 \mathrm{~min} /$ week MVPA $\left.^{\mathrm{a}}, 34 \% \mathrm{TWL}^{\mathrm{b}}\right]$.

Contexts that contribute to negative affect

Use of distraction

"Since it's not something that I enjoy or something that I can do without really thinking about it I have to go out of my way to distract [myself] while I'm doing it in order to keep doing it." [M, age 48, $100 \mathrm{~min} /$ week $\left.\mathrm{MVPA}^{\mathrm{a}}, 8 \% \mathrm{TWL}^{\mathrm{b}}\right]$ 
Table 2 (continued)

Theme Quotation

All or nothing thinking

"I say to myself, 'Okay. Well, I'm going to do it.' But now, once I start doing it, I want to do it sort of regularly, every day, something like that. And if I don't see myself as being able to do that, then I don't do it at all." [F, age 70, $475 \mathrm{~min} /$ week MVPA $\left.{ }^{\mathrm{a}}, 35 \% \mathrm{TWL}^{\mathrm{b}}\right]$.

"So changing my thought pattern has been really helpful with motivation. So again kind of thinking-- instead of looking at exercise as a burden and a thing that needs to be checked off of the list, trying to change to something I get to do and something that is a reward for finishing the day or what have you." [F, age 31, $130 \mathrm{~min} /$ week $\left.\mathrm{MVPA}^{\mathrm{a}}, 33 \% \mathrm{TWL}^{\mathrm{b}}\right]$.

"Yeah. I think before the surgery I would feel like, 'Why bother? Nothing is going to change. I have been trying to lose this weight since I was an adolescent.' When I'm not in a good frame of mind, sometimes I catch those thoughts, right? Where I feel that, for example, like, 'I will never lose my belly fat. It doesn't matter how many core exercises I do.' But then those thoughts, I noticed that I can replace them. The more positive I am, the more easily it is to replace those thoughts with positive thoughts." [F, age 42, $250 \mathrm{~min} /$ week MVPA ${ }^{\mathrm{a}}, 23 \%$ $\mathrm{TWL}^{\mathrm{b}}$ ].

Depression

"I could tell you right now the reason why I'm fighting to get back into the habit of doing the treadmill right now is the thing that broke me of the habit was probably a bout of depression." [M, age 48, $100 \mathrm{~min} /$ week MVPA ${ }^{\mathrm{a}}, 8 \% \mathrm{TWL}^{\mathrm{b}}$ ]

"I would say sometimes when I'm feeling more down or unmotivated due to whatever reason, maybe stress from work or just my mental health or something can make me restrict myself from going." [F, age 21, $420 \mathrm{~min} /$ week $\mathrm{MVPA}^{\mathrm{a}}, 37 \% \mathrm{TWL}^{\mathrm{b}}$ ]

“Kind of a letdown, 'Okay. That's done. What next?' kind of thing. [...] 'I guess that my walk is done, and I come home, and there's-- I don't know. There's nobody here. And it's just me, and maybe because it's done?" [F, age 54, $200 \mathrm{~min} /$ week $^{\mathrm{MVPA}}{ }^{\mathrm{a}}, 41 \% \mathrm{TWL}^{\mathrm{b}}$ ].

Weight loss as primary reason

"People say, 'Well, exercise.' I feel almost at a loss with that because [...] I don't think it's really going to- - unless I really get into it, I don't think it's going to be that dramatic to lose these last 10 pounds." [F, age $70,475 \mathrm{~min} /$ week $\left.\mathrm{MVPA}^{\mathrm{a}}, 35 \% \mathrm{TWL}^{\mathrm{b}}\right]$.

Negative body image

"I'm hoping I get to a point where I can run and do my exercise routine without having to stop or being embarrassed of how I feel and look." [F, age 30, $275 \mathrm{~min} /$ week $^{\mathrm{MVPA}}{ }^{\mathrm{a}}, 51 \%$ $\left.\mathrm{TWL}^{\mathrm{b}}\right]$.

"And then I like rollerblading. But people look at me like my rollerblades are going to break because I'm so heavy. That is not a good feeling." [F, age 40, $0 \mathrm{~min} /$ week MVPA ${ }^{\mathrm{a}}, 37 \%$ $\mathrm{TWL}^{\mathrm{b}}$ ].

"When I was heavy at the various points in my life, I wouldn't go out walking. In fact [...] some years back, I would go out and walk two miles and then jog back and then take my bike out, even when I was heavy, but I was doing it at like 4AM so no one would see me. And now I do it in daylight because I don't have the sensitivity to being judged because of my size, so. [...] I think I feel better now about my body image, obviously than when I was heavy. But that's only been recently. Even though I've lost the weight for a while, I think, finally it's making it to my head that I'm not the image of what I was. And I think a part of that is because of the walking and stuff, so. And I think the walking reinforces positive feelings about my image." [M, age 63, $840 \mathrm{~min} /$ week $\mathrm{MVPA}^{\mathrm{a}}$, 45\% $\mathrm{TWL}^{\mathrm{b}}$ ].

“Sometimes I don't want to do certain exercises when I'm out or when I'm with my daughter just because of how my body looks after the surgery. [...] It makes me think of, are there ways to do certain exercises or do certain things where I don't need to jump up and down and have all my extra skin jumping up and down at different levels?" [F, age 30, $275 \mathrm{~min} /$ week MVPA $\left.^{\mathrm{a}}, 51 \% \mathrm{TWL}^{\mathrm{b}}\right]$.

The COVID-19 pandemic

"Well, I can say this. Today I was really anxious because-I think everybody in the world's very anxious [...] I have my own law practice. My phone is not ringing, so I'm not doing any work, which is making me incredibly anxious in thinking I'm not going to have any work for the next four months. It would be the perfect time for me to go out and take a walk, and yet I'm sitting in the house texting everyone because I'm totally anxious." [F, age $63,0 \mathrm{~min} /$ week $\left.\mathrm{MVPA}^{\mathrm{a}}, 34 \% \mathrm{TWL}^{\mathrm{b}}\right]$.

${ }^{a} M V P A$ moderate-to-vigorous physical activity, ${ }^{b} T W L$ total weight loss 
and also described their perception of physical activity as negative or burdensome.

Because if I was sitting there, watching the clock, and watching the calories kind of slowly tick up, because there's monitors on the machines, that would drive me crazy. So I distract myself by doing these-- with music or playing a game online or watching a video. [M, age 50, $120 \mathrm{~min} /$ week MVPA, $8 \%$ TWL].

This may reflect a lack of mindfulness that was identified as a factor leading to positive affect during physical activity. While participants described distraction as a strategy driven to reduce negative emotions, tuning out from the negative may also inadvertently lead to missing out on potential positive emotions.

Context 2: All or nothing thinking. One way of thinking that contributed to negative affect was an "all or nothing" mindset about physical activity. This manifested in a variety of ways, including the belief that activity must reach a certain threshold to be valuable:

So I' $m$ the type of person that if I'm going to work out, I need to work out every single day. If I don't, I'm just not going to do it at all. [F, age 40, $0 \mathrm{~min} /$ week MVPA, 37\% TWL].

These mindsets may be holding certain participants back from tuning into the more nuanced emotions they might have during activity, instead of focusing only on the negative, or losing the opportunity to have a positive and reinforcing experience because they avoid the activity altogether. Of note, some participants described how they have been working to overcome these cognitive barriers that had formed prior to surgery.

Context 3: Depression. Depression was another context that contributed to negative affect associated with physical activity. Participants who had experienced this noted that it interfered with their routine and would prevent them from getting started:

Lately, my mood hasn't been what it usually is. So, yeah. Definitely, I think that if your mind's not right, I don't see you being able to workout as much. [F, age 33, $0 \mathrm{~min} /$ week MVPA, 15\% TWL].

Context 4: Weight loss as primary reason for exercise. Given that this population had undergone MBS within the past two years, it is logical that weight loss is a primary factor in their motivation to exercise, as this has been such a focus of their health behaviors in recent years. However, sometimes a strong focus on weight loss led to negative feelings about physical activity, through the belief that being more active would not aid weight loss and therefore was not worth doing. One participant shared,
I'd say it's as challenging, if not more challenging to get there, because I know I kind of have a back-up. I know I'm not going to eat as much as I normally will, but so it's almost like I'm less motivated because I've got this surgery now, and I can kind of lean on that as opposed to getting to the gym and eating a better diet regimen. [M, age 50, $120 \mathrm{~min} /$ week MVPA, 8\% TWL].

Context 5: Negative body image. Feeling negative emotions related to one's body image was a barrier to physical activity for some participants. This could be negative body image due to high weight:

Like I said, some days if I'm not really happy with the way I look or I kind of just get discouraged in general with just myself and my body image, it kind of interferes with me wanting to go to the gym. [F, age 21, 420 $\mathrm{min} /$ week MVPA, 38\% TWL].

For many, this barrier had lessened significantly with the weight loss they experienced with surgery, while for others, new body image concerns emerged after surgery related to excess skin. For example,

Sometimes I don't want to do certain exercises when I'm out or when I'm with my daughter just because of how my body looks after the surgery. [...] It makes me think of, are there ways to do certain exercises or do certain things where I don't need to jump up and down and have all my extra skin jumping up and down at different levels? [F, age 30, $275 \mathrm{~min} /$ week MVPA, $51 \%$ TWL].

Context 6: The COVID-19 pandemic. This study was conducted in part (nine interviews) during the COVID-19 pandemic, which some participants identified as a contributor to negative experiences with physical activity. For some, access to their preferred type of activity (e.g., group exercise classes) was impacted, forcing them to engage in a less enjoyable activity and/or resulting in less frequent physical activity. For others, anxiety and depression due to finances or increased childcare responsibilities from the pandemic increased feelings of overwhelm and made exercise feel less doable.

\section{Discussion}

The aim of this study was to better understand emotions people experience related to physical activity after MBS, and the contexts that contribute to their positive and negative emotions. We found that participants noted both positive and negative emotions related to physical activity, with a tendency for an improvement in mood during and after the 
activity compared to before, as has been found in other populations. By describing the ways emotions relate to physical activity, participants provided insight into what helps them succeed, or what is getting in the way.

Participants who were sustaining high levels of physical activity described the types of positive feelings they had while working out (e.g., pride, determination, excitement), as well as certain contexts that contributed to these positive feelings. When examining these experiences through the lens of the Upward Spiral Theory, participants were describing aspects of both the inner loop (positive affect during the activity itself being reinforcing) and the outer loop (building resources and tools to access more pleasurable activities) [9]. For example, finding an enjoyable activity (e.g., Zumba) leads to a more positive experience during the workout. Attending the same class repeatedly could further increase that positive experience as someone develops mastery over the activity and meets others in the class, building a social component. Mindfulness during physical activity can help this population to reflect on the drastic change they have made in their lifestyle and health, and to tune into the benefits (e.g., less pain, increased stamina). The lived experiences fit with the model in explaining why certain participants had been so successful in engaging in consistent physical activity after surgery. Largely, the positive experiences participants described were not unique to their situation post-MBS; finding enjoyable activities, socializing, and building mastery are common features of physical activity that people find to be positive and reinforcing.

Participants did also commonly identify negative affect associated with activity, most frequently anxiety, frustration, and fatigue. In most cases, negative emotion decreased during the workout and was typically gone by the time the person was finished. But sometimes, persistent negative emotion led participants to shorten their workout compared to what they had planned, likely compromising long-term commitment to physical activity. A subset of participants described an emotional experience that was unique from the rest. They were unable to describe any emotion when asked about how they felt during a recent bout of activity, they noted a general strong dislike of exercise, and they mentioned relying on distraction (e.g., TV) to get through a workout. While these participants did identify physical activities they enjoyed, these were not activities they could access regularly (e.g., downhill skiing, being active at a specific social event that only occurs once per year). The activities they were choosing to engage in for health reasons were ones they found boring and lacking enjoyment. These participants could benefit from learning strategies to increase positive emotions related to physical activity to help them build a sustainable physical activity habit.

A variety of cognitive and emotional contextual factors contributed to the negative affect participants experienced.
Certain beliefs, like that the idea that exercise is not valuable if it is not leading to weight loss or is below a certain threshold, held some participants back from engaging in activity. These beliefs led to feelings of frustration when they did engage but were not reaching the level they consider a success. Feeling embarrassed about one's body got in the way for some participants, and depression was another barrier identified. These negative contexts were more specific to the experience of living with obesity than were the contexts contributing to positive emotions in participants. These specific negative factors could be leading individuals who have had MBS to "miss out" on the reinforcing nature of physical activity described in the Upward Spiral Theory, which requires positive affect to take effect.

These results provide helpful information for the development of a physical activity intervention that targets the unique barriers to activity that post-MBS patients may experience. Experiences of participants who were consistently exercising along with the framework from the Upward Spiral Theory demonstrate that tuning into positive feelings such as pride and determination, as well as finding activities that feel enjoyable, help individuals to continue their physical activity regimen [9]. Enjoyable activities come in different forms; for some, a high-energy exercise class like Zumba brings a lot of joy due to the music, movement, and social aspect. Others find enjoyment from activities that feel productive such as yard work or walking for transportation. Others noted the outdoors as a factor that increased enjoyment. For some, tracking performance and improvement was very motivating. If individuals are struggling to maintain physical activity, guiding them in finding activities that bring joy and in tuning into the positive emotions they may be ignoring during activity could help them to make a successful change.

Intervention targets were also identified from the experiences of participants who noted negative affect. For example, all or nothing thinking about physical activity can be targeted with cognitive reappraisal techniques. Overuse of distraction can be addressed with mindfulness training [30]. An excessive focus on exercise only for weight loss can be addressed with values work and with education about other benefits of physical activity that are independent of weight [31]. For some, teaching strategies to cope with negative body image can open up options for exercising comfortably.

Strengths of this study included in-depth, focused interviews with racially/ethnically diverse participants about the emotions they experience in relation to physical activity, in the context of a recent MBS. This type of data collection is critical in early intervention development stages per the ORBIT model [12]. Limitations included self-reported physical activity levels, which were likely over-reported [32], the low participation rate, and the single recruitment site, potentially limiting the transferability of findings. The study partially took place during the COVID-19 pandemic, 
which may have affected results. Specifically, some participants interviewed during the pandemic discussed pandemicrelated barriers to activity (lack of access to certain types of physical activity, increased anxiety) that may not have existed in another time period.

In conclusion, emotional factors related to physical activity are important to consider when encouraging behavior change after MBS. This population, while also experiencing the typical barriers to physical activity that are common across society, is unique in their recent major step toward improving their health and making a lifestyle change. Therefore they are at a stage where they may be especially open to making changes, but also have unique emotional concerns that may hinder successful adoption of the high level of physical activity that is recommended to aid weight loss maintenance and prevent future disease.

Supplementary Information The online version contains supplementary material available at https://doi.org/10.1007/s11695-021-05807-x.

Funding This study was funded by the National Institutes of Health (HLK23148017) (PI: Feig).

\section{Declarations}

Ethical Approval All procedures performed in studies involving human participants were in accordance with the ethical standards of the institutional and/or national research committee and with the 1964 Helsinki declaration and its later amendments or comparable ethical standards.

Informed Consent Informed consent was obtained from all individual participants included in the study.

Conflict of Interest The authors declare no competing interests.

\section{References}

1. Courcoulas AP, King WC, Belle SH, et al. Seven-year weight trajectories and health outcomes in the Longitudinal Assessment of Bariatric Surgery (LABS) study. JAMA Surg. 2018;153:427-34. https://doi.org/10.1001/jamasurg.2017.5025.

2. Carretero-Ruiz A, del Carmen Olvera-PorcelCavero-Redondo MI, et al. Effects of exercise training on weight loss in patients who have undergone bariatric surgery: a systematic review and metaanalysis of controlled trials. Obes Surg. 2019;29:3371-84.

3. King WC, Chen JY, Bond DS, et al. Objective assessment of changes in physical activity and sedentary behavior: pre- through 3 years post-bariatric surgery. Obesity. 2015;23:1143-50. https:// doi.org/10.1002/oby.21106.

4. Barbosa CGR, Verlengia R, Silva AG, et al. Changes in physical activities patterns assessed by accelerometry after bariatric surgery: a systematic review and meta-analysis. Obes Med. 2019;13:6-12. https://doi.org/10.1016/j.obmed.2018.12.003.

5. Catenacci VA, Grunwald GK, Ingebrigtsen JP, et al. Physical activity patterns using accelerometry in the national weight control registry. Obesity. 2011;19:1163-70. https://doi.org/10.1038/OBY.2010.264.
6. Han SY, Agostini G, Brewis AA, Wutich A. Avoiding exercise mediates the effects of internalized and experienced weight stigma on physical activity in the years following bariatric surgery. BMC Obes. 2018;5:18. https://doi.org/10.1186/ s40608-018-0195-3.

7. Wrzosek M, Wiśniewska K, Sawicka A, et al. Early onset of obesity and adult onset of obesity as factors affecting patient characteristics prior to bariatric surgery. Obes Surg. 2018;28:3902-9. https://doi.org/10.1007/s11695-018-3381-y.

8. Zabatiero J, Smith A, Hill K, et al. Do factors related to participation in physical activity change following restrictive bariatric surgery? A qualitative study. Obes Res Clin Pract. 2018;12:307-16. https://doi.org/10.1016/j.orcp.2017.11.001.

9. Van Cappellen P, Rice EL, Catalino LI, Fredrickson BL. Positive affective processes underlie positive health behaviour change. Psychol Heal. 2018;33:77-97. https://doi.org/10.1080/08870446. 2017.1320798.

10. Ekkekakis P, Lind E, Vazou S. Affective responses to increasing levels of exercise intensity in normal-weight, overweight, and obese middle-aged women. Obesity. 2010;18:79-85. https://doi. org/10.1038/oby.2009.204.

11. Peacock JC, Sloan SS, Cripps B. A qualitative analysis of bariatric patients' post-surgical barriers to exercise. Obes Surg. 2014;24:292-8. https://doi.org/10.1007/s11695-013-1088-7.

12. Czajkowski SM, Powell LH, Adler N, et al. From ideas to efficacy: The ORBIT model for developing behavioral treatments for chronic diseases. Heal Psychol. 2015;34:971-82. https://doi.org/ 10.1037/hea0000161.

13. Callahan CM, Unverzagt FW, Hui SL, et al. Six-item screener to identify cognitive impairment among potential subjects for clinical research. Med Care. 2002;40:771-81. https://doi.org/10.1097/ 00005650-200209000-00007.

14. Pinninti NR, Madison H, Musser E, Rissmiller D. MINI International Neuropsychiatric Schedule: clinical utility and patient acceptance. Eur Psychiatry. 2003;18:361-4. https://doi.org/10. 1016/j.eurpsy.2003.03.004.

15. Bohn MJ, Babor TF, Kranzler HR. The Alcohol Use Disorders Identification Test (AUDIT): validation of a screening instrument for use in medical settings. J Stud Alcohol. 1995;56:423-32. https://doi.org/10.15288/jsa.1995.56.423.

16. Yudko E, Lozhkina O, Fouts A. A comprehensive review of the psychometric properties of the Drug Abuse Screening Test. J Subst Abuse Treat. 2007;32:189-98. https://doi.org/10.1016/j. jsat.2006.08.002.

17. Patton M. Qualitative research \& evaluation methods: integrating theory and practice. 4 th ed. Thousand Oaks: SAGE Publications; 2015.

18. Piercy KL, Troiano RP, Ballard RM, et al. The physical activity guidelines for Americans. JAMA - J Am Med Assoc. 2018;320:2020-8. https://doi.org/10.1001/jama.2018.14854.

19. Craig CL, Marshall AL, Sjöström M, et al. International physical activity questionnaire: 12 -country reliability and validity. Med Sci Sports Exerc. 2003;35:1381-95. https://doi.org/10.1249/01.MSS. 0000078924.61453.FB.

20. Scheier MF, Carver CS, Bridges MW. Distinguishing optimism from neuroticism (and trait anxiety, self-mastery, and self-esteem): a reevaluation of the Life Orientation Test. J Pers Soc Psychol. 1994;67:1063-78. https://doi.org/10.1037/0022-3514.67.6.1063.

21. Watson D, Clark LA, Tellegen A. Development and validation of brief measures of positive and negative affect: the PANAS scales. J Pers Soc Psychol. 1988;54:1063-70. https://doi.org/10.1037/ 0022-3514.54.6.1063.

22. Bjelland I, Dahl A, Haug TT, Neckelmann D. The validity of the Hospital Anxiety and Depression Scale. An updated literature review. J Psychosom Res. 2002;52:69-77. https://doi.org/10.1016/ S0022-3999(01)00296-3. 
23. U.S. Department of Health and Human Services, Public Health Service, Centers for Disease Control and Prevention, National Center for Chronic Disease Prevention and Health Promotion, Division of Nutrition and Physical Activity. Barriers to Being Active Quiz. In: Promoting Physical Activity: A Guide for Community Action Champaign, IL: Human Kinetics; 1999. pp. 100-101.

24. Resnick B, Jenkins LS. Testing the reliability and validity of the self-efficacy for exercise scale. Nurs Res. 2000;49:154-9. https:// doi.org/10.1097/00006199-200005000-00007.

25. Pearl RL, Puhl RM. Measuring internalized weight attitudes across body weight categories: validation of the Modified Weight Bias Internalization Scale. Body Image. 2014;11:89-92. https:// doi.org/10.1016/j.bodyim.2013.09.005.

26. Drabble L, Trocki KF, Salcedo B, et al. Conducting qualitative interviews by telephone: lessons learned from a study of alcohol use among sexual minority and heterosexual women. Qual Soc Work. 2016;15:118-33. https://doi.org/10.1177/1473325015585613.

27. Huffman JC, Dubois CM, Mastromauro CA, et al. Positive psychological states and health behaviors in acute coronary syndrome patients: a qualitative study. J Health Psychol. 2016;21:1026-36. https://doi.org/10.1177/1359105314544135.
28. Saunders B, Sim J, Kingstone T, et al. Saturation in qualitative research: exploring its conceptualization and operationalization. Qual Quant. 2018;52:1893-907. https://doi.org/10.1007/ s11135-017-0574-8.

29. Pearl RL, Hopkins CH, Berkowitz RI, Wadden TA. Group cognitive-behavioral treatment for internalized weight stigma: a pilot study. Eat Weight Disord. 2018;23:357-62. https://doi.org/10. 1007/s40519-016-0336-y.

30. Schneider J, Malinowski P, Watson PM, Lattimore P. The role of mindfulness in physical activity: a systematic review. Obes Rev. 2019;20:448-63. https://doi.org/10.1111/obr.12795.

31. Warburton DER, Bredin SSD. Health benefits of physical activity: a systematic review of current systematic reviews. Curr Opin Cardiol. 2017;32:541-56.

32. Bond DS, Jakicic JM, Unick JL, et al. Pre- to postoperative physical activity changes in bariatric surgery patients: self report vs. objective measures. Obesity (Silver Spring). 2010;18:2395-7. https://doi.org/10.1038/oby.2010.88.

Publisher's Note Springer Nature remains neutral with regard to jurisdictional claims in published maps and institutional affiliations. 